\title{
Developing resilience throughout the continuum of medical education
}

\author{
Vimmi Passi
}

Published online: 14 November 2014

(C) The Author(s) 2014. This article is published with open access at Springerlink.com

The thought provoking paper by Dr Outram on 'you teach us to listen ... but you don't teach us about suffering-self-care and resilience strategies in medical education,' highlights the importance for medical educators to consider methods to develop resilience [1]. There has been a recent explosion of interest in teaching and learning resilience in medical education [2-4]. This commentary explores the vital need for medical leaders to develop resilience throughout the continuum of medical education. It is now imperative for medical educators worldwide to collaborate and consider methods to develop resilience for 21 st century doctors. We have a duty to support our students and maintain high professional standards of clinical care for our patients.

Resilience is an emotional competence and can be considered as behaviour to be acquired during training [5, p 343]. It consists of cognitive processes that encompass at least four dimensions: self-efficacy; planning; self-control; commitment and perseverance $[4,6]$. Interestingly, although there are many definitions of medical professionalism [7], none of the definitions include resilience as a theme. Resilience is a new agenda in education and this commentary explores the importance of developing resilience throughout the continuum of medical education.

The main aim of the medical school curriculum is to develop competent, professional and compassionate doctors. However, studies suggest that mental health worsens after students begin medical school and remains poor throughout training [8]. Life satisfaction has also shown to be reduced during medical school [9]. Potential causes of student distress include adjustment to the medical school environment, ethical conflicts, exposure to death and human suffering, personal life events and educational debt [8]. Therefore, medical educators need to support students to develop resilience throughout the curriculum in their journey to becoming a doctor. This is

\footnotetext{
V. Passi $(\bowtie)$

Masters in Medical Education Masters and CPD Team Warwick Medical School, The University of Warwick, Coventry CV4 7AL, England

email: vimmi.passi@warwick.ac.uk

URL: http://www.warwick.ac.uk/wms
} 
imperative to avoid the consequences of student distress which include worsening academic performance [10]; loss of empathy [11] and suicide [12].

The journey throughout postgraduate training is exciting but requires both personal and professional resilience. Personal resilience is required in situations as described in Dr Outram's article regarding 'managing sad and painful parts of medicine,' - junior doctors will need to develop skills in 'breaking bad news,' patient suffering and end of life care [1]. Professional resilience is required as junior doctors will need to work in different educational environments; there are pressures of postgraduate exams and important decisions to be made regarding their future carer pathway. It is imperative that clinical and educational supervisors support their students and help them develop personal and professional resilience.

The need to develop and maintain resilience continues throughout a doctor's career. For senior doctors - there are challenges of maintaining effective patient services, work-life balance and workload. Burnout is a frequent phenomenon in experienced practitioners and the most widely used instrument to measure burnout is the Maslach Burnout Inventory (MBI), a questionnaire of 27 items with three subscales [13]. According to Maslach, burnout occurs when three criteria are met: high emotional exhaustion, high depersonalisation and low personal achievement. Medical educators need to conduct further research on burnout to identify the effect of burnout on the mental health of the doctor, the impact on patient care and educational interventions to reduce burn out in doctors.

The challenge for educators is to develop effective, innovative methods within the curriculum to enhance resilience. Dr Outram's article effectively highlights promising interventions including the importance of a self-care curriculum. However, further research is required on the ways in which resilience can be developed and supported during and after clinical training [4]. Secondly, there is research which suggests that looking at personality traits is more reliable than assessing single measures of resilience or stress. Four personality traits in particular have a strong influence on one's capacity for developing resilience: self-directedness, cooperativeness, harm avoidance and persistence [14]. Finally, there is no consensus definition of resilience in medical education and this could be valuable for students in understanding the importance of this theme throughout their training.

In summary, developing resilience is an important theme that should be considered a key component in medical professionalism. Developing resilience is particularly important in medicine because of the demanding workloads, societal expectations and government policies [3]. Medical educators need to consider methods to promote resilience and offer support to students and colleagues at all stages of their careers. This is an exciting opportunity and medical leaders worldwide need to embrace the importance of developing a resilient, enthusiastic and passionate future medical workforce.

'The practice of medicine is an art, not a trade; a calling, not a business; a calling in which your heart will be exercised equally with your head. Often the best part of your work will have nothing to do with potions and powders, but with the exercise of an influence of the strong upon the weak, of the righteous upon the wicked, of the wise upon the foolish.' (Sir William Osler 1849-1919). 
Open Access This article is distributed under the terms of the Creative Commons Attribution License which permits any use, distribution, and reproduction in any medium, provided the original author(s) and the source are credited.

\section{References}

1. Outram S. You teach us to listen,... but you don't teach us about suffering': self-care and resilience strategies in medical school curricula. Perspect Med Educ. 2014. doi:10.1007/s40037-014-0145-9.

2. Haglund M, Cooperm N, Nestadtm PS, Muller D, Southwick SM. Resilience in the third year of medical school: a prospective study of the associations between stressful events occurring during clinical rotations and student well-being. Acad Med. 2009;8:258-68.

3. McAllister M, McKinnon J. The importance of teaching and learning resilience in the health disciplines: a critical review of the literature. Nurse Educ Today. 2009;29:371-9.

4. Howe A, Smajdor A, Stockl A. Towards an understanding of resilience and its relevance to medical training. Med Educ. 2012;46:349-56.

5. Tempski P, Martins MA, Paro H. Teaching and learning resilience: a new agenda in medical education. Med Educ. 2012;46:343-8.

6. Atkinson PA, Martin CR, Rankin J. Resilience revisited. J Psychiatr Ment Health Nurs. 2009;16:137-45.

7. Passi V, Doug M, Peile E, Thistlethwaite J, Johnson N. Developing medical professionalism in future doctors: a systematic review. Int: J Med Educ; 2010. p. 119-29.

8. Dyrbye LN, Thomas MR, Shanafelt TD. Medical student distress: causes, consequences and proposed solutions. Mayo Clin Proc. 2005;80(12):1613-22.

9. Kjeldstadli K, Tyssen R, Finset A, et al. Life satisfaction and resilience in medical school—a six year longitudinal nationwide and comparative study. BMC Med Educ. 2006;6:48.

10. Stewart SM, Lam TH, Betson CL, Wong CM, Wong AM. A prospective analysis of stress and academic performance in the first two years of medical school. Med Educ. 1999;33:243-50.

11. Hojat M, Mangione S, Nasca T, et al. An empirical study of decline in empathy in medical school. Med Educ. 2004;38:934-41.

12. Hays L, Cheever T, Patel P. Medical student suicide, 1989-1994. Am J Psychiatry. 1996;153:553-5.

13. Maslach C, Leiter MP. Early predictors of job burnout and engagement. J Appl Psychol. 2008;93:498-512.

14. Tyssen RD, Rovik FC, Thorkildsen JO, et al. Personality traits and tyoes predict medical school stress: a six year longitudinal and nationwide study. Med Educ. 2007;41:781-7.

Vimmi Passi works as a General Practitioner and Trainer. She is the Course Director for the Masters in Medical Education Programme at Warwick University, UK. Her research interest is in the development of medical professionalism. 